\title{
Resource Management in New Zealand: Rhetoric, Reality and Reform
}

\section{Veronica Jacobsen}

7 he Resource Management Act 1991 (RMA) was developed and implemented during a period of wide-scale reform in New Zealand and L amalgamated a large number of statutes and regulations dealing with resources and the natural environment into a single comprehensive and integrated framework. It is the principal means of regulating the use of New Zealand's natural resources to promote their sustainable management. The rhetoric of the reform process was environmentalist; the very title reflects the apparent faith of environmentalists in the ability of governments to manage the environment (Greve and Smith, 1992). A dearth of data makes it impossible to assess whether the reality has lived up to the statutory goal of sustainability. Local government has not embraced effects-based resource management and the use of market mechanisms in practice, and the broad statutory definition of the environment allows local government scope to regulate activities for social and economic purposes rather than more narrow environmental effects. The difficulties and widespread dissatisfaction with the Act have led to Government proposals for reform to refocus the Act on the natural and physical environment and to curb the use of command and control regulation. Predictably, such limits on the policy and regulatory discretion of councils are opposed by environmental groups who continue to place reliance on the ability of councils to achieve sustainable resource management.

\section{Background}

The publication of Rachel Carson's Silent Spring marked a growing belief that economic development, population increase and technological advances contributed to environmental damage. It was followed by debates in the 1960s about population growth and in the 1970 s about energy depletion and conservation that are still current today (Perkins and Thorns, 1997). In New Zealand the 'green' movement grew in opposition to state-sponsored, environmentally damaging 'Think Big' projects and government policies of the 1970 s and early 1980 s which exploited resources to promote economic growth. As late as 1984, for example, farmers received government subsidies to clear

Veronica Jacobsen is Senior Manager at Arthur Andersen, Wellington and Lecturer at the University of Waikato, Hamilton. 
forest and marginal land for agriculture. At the same time, an active environmental lobby developed to oppose mining, particularly on the Coromandel Peninsula, which was experiencing a resurgence of prospecting activity following a rise in the gold price. The movement also lobbied to protect the environment, for example to prevent the raising of the level of Lake Manapouri as part of a hydroelectric scheme and to preserve South Island beech forests. The environmental movement was concerned that the Town and Country Planning Act 1977 (TCPA) did little to protect the natural environment, as its primary focus was planning for urban development and infrastructure (Memon and Perkins, 1993).

The TCPA reflected the economic and political climate of the time. This was the high water mark of the planning approach to economic development with wide public intervention in markets and the use of public sector agencies to achieve economic and social goals. The purpose of the Act was 'the wise use and management of resources' and 'the direction and control of ... development' to promote health, safety, convenience and economic, cultural, social and general welfare. It reflected an almost Keynesian belief in the natural ability of government to achieve these goals through centralised planning.

This Act marked a significant departure from the previous, more circumscribed view of planning which had dealt primarily with site-related externalities and the imposition of community values on the use of private property. In essence, the purpose of the Act was the direction and control of virtually all forms of development. It extended the scope of the planning process beyond the orderly organisation of development to the social and economic management of the urban environment (including issues such as housing and employment) as well as the control of land use. Its approach is exemplified in 'its listing of 'matters of national importance' that included the 'avoidance and encroachment on, and the protection of, land having a high actual or potential value for the production of food'.

The business community was critical of the Act for different reasons from environmentalists. It was seen as a barrier to economic development, and it imposed very high compliance costs on business through the financial costs and delays of the planning and permit process where responsibility to the environment was fragmented across government departments and local bodies. At the same time, the management of the Act was costly to local, regional and national government. Dissatisfaction with the Act and the complexity of environmental management under a plethora of statutes and regulations culminated in a review of the Act by Anthony Hearn (1987).

The outcome of the review and the long reform process that followed was the Resource Management Act 1991. It too was a product of its time, built on the idea of sustainable management enunciated in the Bruntland Report (1987), although there was considerable debate at the time whether the focus should be on sustainable development or sustainable management. The preference of the 
business community was for sustainable development, but environmentalists wanted to avoid connotations of development by using the term management. It also reflected international trends towards decentralisation and deregulation as well as ideas of efficiency that were at the heart of the Labour government's economic and public sector reforms (Frieder, 1997). Local government was reformed at the same time, and given a central role in the administration of the new legislation. Although Crown-owned minerals such as gold and petroleum were originally envisaged as being incorporated into this portmanteau statute, the inherent tension between sustainable management and mineral extraction resulted in the passage of a separate Crown Minerals Act 1991.

The RMA addressed some of the problems of compliance costs that had faced all the parties under the previous regulatory regime. It integrates the management of natural resources within a single statute, thereby providing 'onestop shopping' for consents previously granted under several separate Acts. It also imposes time limits on councils in the granting of consents in order to speed up the application process, although it provides them with the scope for delaying behaviour by requests for more information from applicants. The decentralisation of resource management to regional and local government reduced the problems associated with overlapping and often conflicting jurisdictions under the previous system. These administrative advantages, however, were overshadowed by the expected improvements in environmental outcomes from the bold, innovative, integrated and holistic approach to resource management that coupled economic efficiency with ecological sustainability.

\section{The Rhetoric}

The RMA encompasses several principles of resource management which have far-reaching consequences. First, the objective of the Act is to 'promote the sustainable management of natural and physical resources'. The underlying presumption is that government management of resources is required in order to promote sustainable resource use and provide for the needs of future generations. The very title of the statute reflects a view that government, rather than landowners, is primarily responsible for ensuring that resources are managed in a sustainable fashion, reducing the role of private property in protecting the environment and managing resources. This implies a heavy load for government in terms of the information required for sustainable management.

Second, the Crown is the presumed owner of all rights related to natural resources, so that what is not expressly permitted is forbidden. The legislation treats the use of private property as a privilege conferred by the regulatory body. In order to prevent the imposition of externalities on others, private rights to use land were previously attenuated, for example by the TCPA. However, the freedom of farmers to develop their land was not challenged, and regulations 
to control the clearance of native vegetation to protect water and soil were not enforced (Wilson, 1994). Under the RMA the landowner has no rights other than those granted by the council. This treatment of property rights differed significantly from other contemporary reforms, such as the removal of import licensing, that restored private property rights and removed government attenuation of those rights (Savage and Bollard, 1990). Resource consents are required to undertake all activities that are not classified as prohibited activities or existing uses under the plan. Under this provision, resource consents are not required for existing uses such as existing housing, much of which might not be built under current building requirements.

This formulation effectively weakens private ownership rights and their corresponding incentives for careful resource management. In contrast, it grants councils enormous power over private land use, enabling them to prevent various activities from the removal of vegetation to the erection of a tent on the land (McShane, 1998). The requirement for resource consents for any new activity is a powerful disincentive for innovation and new developments when coupled with the costly and uncertain process of obtaining them. It allows councils wide discretion, with the result that some are more developmentfriendly than others. Developers and other land users soon get to know which councils are tolerant and professional in their treatment of applications for resource consents.

Third, the Act seeks to promote resource management that focuses on the effects of activities, rather than on the control of activities themselves. Zoning was a tool available to planners under the TCPA that categorised land use according to the activities that were permitted in each zone. Zoning was also an essential element of the planning and direction of activities to promote the planners' vision of social welfare. Zoning for new housing for example, often did not permit 'undesirable' activities such as retail shops, so that residents had to travel long distances to buy necessities such as milk and bread.

The reform process saw zoning as inefficient because of its focus on activities themselves, rather than any negative external effects they generated. An emphasis on external effects, in contrast, was seen to permit a range of activities without any need to regulate the activities themselves. It would also encourage the development and use of new technologies to reduce the impact of external effects. The underlying premise of the Act is that generators of externalities should internalise the negative environmental costs of their activities and thus improve both the efficiency and equity of resource use. The statute is intended to prevent firms and individuals from imposing these costs on others. Dynamic efficiency and environmental protection would be promoted simultaneously.

Fourth, the Act is intended to encourage the use of market mechanisms and to curb the use of interventionist command and control measures often preferred by planners. The economic nature of this effects-based approach is underscored 
by a broad obligation on councils to consider the costs and benefits of a range of alternative means of achieving their goals (Sharp, 1994). Under a performance standards-based approach there may be numerous ways of reaching a given environmental objective. The Act establishes a set of regulatory principles to ensure that if intervention is required, all the alternatives are considered (including doing nothing), the reasons for and against intervention are identified, the costs and benefits are assessed, and the intervention adopted is efficient and effective.

This test requires the assessment of a wide range of policy alternatives, including market mechanisms and prescriptive regulation. It was clearly intended to enable councils to move away from an interventionist planning approach to land use control and to develop and use market mechanisms such as tradeable permits to control the negative effects of activities and so promote better resource management. The cost-benefit analysis it implies and the focus on the effects of activities represented an important economics-based counterpoint to the environmental focus of the Act.

Yet it imposes significant compliance costs on councils. Proper cost-benefit analysis can require a lot of information. Although apparently objective, it also involves a large degree of subjectivity. The data and results are open to different interpretations and challenge by those potentially affected. Comparative analysis of this kind involves a very different way of thinking about policies and rules than planners had used previously.

Fifth, broad public participation in the resource management process is encouraged by the Act. The public has the right to be heard in decisions related to resource use at the planning stage, and in applications for resource consents. Members of the public also have the right to appeal to the Environment Court. The legislation also recognises the importance of Maori as partners under the Treaty of Waitangi and imposes a broad duty to consult with Maori. The underlying philosophy is the encouragement of community-based decisionmaking in a way that reflects local values and preferences. While these provisions are politically popular, particularly among environmentalists who can use them to block development, they have the effect of granting rights to those who do not have to bear the costs of exercising them but can enjoy the benefits.

Finally, the community basis of decision-making is reflected in the decentralisation of resource management to local, rather than central government. The legislation establishes a cascade of responsibilities. Central government is responsible for setting policy on matters of national importance and monitoring the implementation of the Act. Regional councils, which typically cover a large geographical area, are responsible for the management of water, soil and geothermal resources in the region. They also control pollution and the effects of land management on natural resources. Territorial authorities (generally town, city and district councils) are responsible for land use management, subdivision and noise control. 


\section{The Reality}

The RMA is coming under increasing scrutiny after eight years of operation. In part, this is simply part of any evolutionary process. However, it also reflects dissatisfaction with the operation of the legislation, its effects and its underlying approach (McShane, 1998; Frieder, 1997).

The Act is working well in a number of areas compared with the past. The joint hearing procedure makes it faster for applicants to obtain consents than was the case under the previous, fragmented legislation (Dormer, 1994). A large number of consent applications are non-notified, so that they are granted without any lengthy hearings procedure. There is considerable support for the objectives of the Act in terms of the protection of the bio-physical environment (Ministry for the Environment, 1998).

Nevertheless, there remain significant problems with the implementation of the Act. Some of these are highlighted in the report by Owen McShane (1998) which was commissioned by the Minister for the Environment to stimulate discussion on the Act. There is considerable variability of council performance. A particular difficulty is that applicants for resource consents face high compliance costs as a result of delays. A significant number of applications are processed outside the statutory time limits. Such delays can act as a disincentive to investment. Another problem is the amount of information that is required of applicants, with no assurance that a consent will be forthcoming. These and other problems mean that investors and developers can be deterred from even applying for a resource consent. There is simply no way to measure how many activities do not go ahead simply because the Act makes it all 'too hard'. Consequently, the true cost of the legislation is likely to be underestimated.

However, there are more fundamental problems with the legislation. First, resource management in practice is not really effects-based as was contemplated. The Act was intended to require councils to focus on the effects of activities, rather than regulating the activities themselves. Nevertheless, councils have considerable scope to make decisions based on social and economic factors. The Town and Country Planning Act 1977 is reflected in both the policies and plans of the councils and the approaches of council planners under the RMA, reflecting a high degree of path dependency among the people involved despite the sweeping changes of the legislation (North, 1990). One example of this is the extent to which attention is given to the protection of soils in plans, a fact that is exacerbated by the wide definition of the environment in the legislation.

These planning practices are facilitated by provisions within the Act, which require officials to take into account amenity values, and the 'finite characteristics of natural and physical resources' (section 7). At the same the definition of the environment in the Act is not limited to natural and physical resources but encompasses social, economic, aesthetic and cultural considerations. The wording of the Act itself undermines the effects focus by 
restricting 'uses' and 'activities' and by requiring councils to define activities as non-complying, prohibited or permitted. All these factors encourage councils and planners to consider the environment in a very wide sense and to regulate activities for their broad social and economic implications rather than concentrate on the narrow effects of activities on the physical environment. The emphasis on the finite nature of resources also leads to planning decisions that control activities to preserve them for future generations. An apparent belief in an imminent depletion crisis is reflected especially in planning to preserve soils. Regulatory controls of this sort do not reflect any understanding of the role of prices in reflecting scarcity and so do not allow the market system to respond to expected depletion.

The RMA focus on land use controls, rather than on the effects of activities has made property rights indeterminate and created uncertainty for landowners. The RMA gives councils very wide powers to regulate activities on private land. It is not clear what rights, for example, farmers have. Does a dairy farmer have a right to convert to beef or sheep farming, forestry or eco-tourism? What rights does a farmer have over a man-made duckpond that is designated as a protected Significant Natural Area (SNA) in the district plan? Many farmers in the Far North of New Zealand face having large parts of their property being designated as SNAs, with the result that their farm values will fall. While rights over land use were attenuated under the TCPA, the impact of the RMA has been to restrict rights beyond the expectations of landowners. Changing the expectations of what landowners can do with their land without compensation can have a serious financial impact on land values. It can also lead to perverse consequences, as a landowner with a small stand of emergent native vegetation may choose to clear it rather than having it grow and be protected as an SNA under the District Plan. The consequence is that property rights are being defined in the political market in challenges to councils through the submissions and appeals process and through lobbying and publicity campaigns.

The Act does not provide compensation for regulatory takings imposed through the planning or resource consent process. Takings of this kind are 'free' to regulators who do not have to bear the costs of their decisions, although they may impose substantial costs on the landowners affected. The planning and resource consents process thus becomes a rent-clearing house, benefiting some at the expense of others. Landowners potentially detrimentally affected by the land use decisions of neighbours have strong incentives to use the resource consent process to promote their own interests. With no limit on standing, anyone else can also object to a resource consent. The wide definition of the environment means that objections are not limited to the expected physical effects of land use, and can include matters such as traffic congestion and the effects on business. Businesses can and do use the Act as a defensive weapon to stifle competition from new entrants. 
Secondly, the Act did not result in the expected replacement of command and control measures with market mechanisms. Section 32 was meant to force councils to consider the costs and benefits of a range of alternative mechanisms. The provision was intended to foster the use of market mechanisms, where appropriate, to control externalities and do nothing where this would result in a better outcome than any intervention. Councils typically do not go through a full section 32 process to determine whether alternatives to regulation are the least cost means of achieving the objective. Despite the cost-benefit test, economic analysis is not routinely used in the planning and resource consent process (Wheeler, 1998). Landowner challenges to see whether councils have complied with the provision have found they have not, simply relying on a perceived need for restrictive controls to promote sustainability (Little, 1998).

Thirdly, the wide public participation encouraged by the Act does not appear to have pleased anyone. There has been enormous input into the planning process by a wide range of organisations, including industry, landowners, environmental, landowner, ratepayer and Maori groups. The need to respond to draft plans and policies, submissions and resource consent hearings imposes high costs on all those involved. At the same time, many groups have questioned the efficacy of the process, as they do not appear to be effective in determining plans and policies. Community views are not necessarily reflected in plans, and community groups have expressed intense dissatisfaction with some draft plans. Farmers in particular have significant concerns about the removal of their property rights over their land through regulation without compensation. The draft plan of Far North District Council that removed the rights of farmers over native vegetation on their land was so vigorously resisted that it was withdrawn. The dichotomy in some areas between the views of the wider community and council may reflect some capture of the process by planning staff.

Provisions for broad public participation particularly encouraged environmentalists to become active in the planning and consents process. This provided stakeholders with the opportunity to seek restrictions on the property rights of landowners through the power of the council. Coupled with the Act's broad interpretation of the environment, this created opportunities for rent seeking and leverage by those seeking enhanced environmental protection. The opportunity for wide public participation and the broad duties for consultation can impose significant costs on applicants during the consents process.

These difficulties in the legislation typically have a regressive and chilling impact. Large businesses can withstand the costs and delays of the consents process more easily than small businesses and individuals. Compliance costs have probably deterred businesses from starting up as a result of the formidable consents process. In any event, the consents process itself can create perverse incentives, with landowners for example, clearing land of native vegetation before applying for a consent in order to avoid a protracted wrangle over the protection of indigenous flora. 


\section{The Reform}

The difficulties and widespread dissatisfaction with the implementation of the RMA have recently led to a review and re-evaluation of the Act. The Minister for the Environment has announced a number of reforms aimed at refocussing the Act on the effects on activities on the natural and physical environment while promoting sustainable resource management. Opponents of the reforms predict that the changes will bias decisions in favour of development and be bad for the environment and democracy. The proposed reforms cover several key areas.

The resource consents process will be made more efficient. Contestability will be introduced into the process by allowing applicants to select among a pool of accredited persons to process their application up to the decision phase. Contestability will create incentives for faster and perhaps cheaper processing and will force councils to specify the objectives of plans clearly and unambiguously. The appointment of independent professional commissioners to make decisions on consent applications will separate the policy and quasi-judicial functions of local government. Councils will be limited to policy-making in regional and district plans. This reform is intended to overcome the referee and player problem inherent in the current system where the council both makes policy and makes determinations in resource consent hearings. It is also expected to improve the quality of decision-making, particularly where applications are highly technical and information-intensive. Appeals on hearings will be limited to points of law, in contrast to the present practice where appeals are heard de novo. Limiting appeals in this way is expected to reduce costs and delays as well as opportunities for strategic behaviour by the parties.

The requirement that regulation be justified by a benefit-cost analysis will be strengthened to encourage further the use of market-based initiatives and curb the use of command and control mechanisms in environmental protection. The provisions under section 32, while well-intentioned, have not been effective in restricting regulation only to those areas where it has a comparative advantage.

The effects-based orientation of the legislation will be strengthened by redefining the environment and clarifying the role of subdivision controls. Subdivision controls will remain within the Act, but will be defined in a way that emphasises that they are useful tools to manage land use, rather than a means of regulating an activity that is per se undesirable. In contrast to the current legislation, subdivision will be permitted unless it is controlled by a plan. The scope for social engineering by councils and planners and the use of the Act to stifle trade competition will be limited by sharpening the focus of resource management to remove the social and economic component from the definition of the environment.

The RMA provides an illustration of the process of institutional evolution. The New Institutional Economics view is that institutional change occurs when the existing structure imposes losses sufficiently high to make change 
worthwhile (Barlow and Quizon, 1993; Alston, Eggertsson and North, 1996). More efficient institutions develop as the parties affected come to recognise and act on new benefit-cost possibilities. Change is driven by individual and group perceptions about the existing arrangements and alternative possibilities. Change may deliver either efficiency gains from the new rules or may involve transfers to one group at the expense of another. In any event, those expecting to benefit are likely to seek change when it is worthwhile for them to do so.

The legislative reform process that led to the RMA began as an efficiency enhancing response to the costs involved under the previous patchwork of legislation. These costs primarily arose from a fragmented and overlapping regulatory framework that imposed significant compliance costs and delays on resource users. The debate however, rapidly began to centre around issues of sustainability and a perception of a resource depletion crisis. The arguments were linked to a world-wide trend of strengthening environmentalism. New Zealand's past history of environmental damage, from species extinction to pest importation to erosion to mine tailings was paraded as an example of poor environmental management.

However, the causes of the past environmental damage were not addressed during this debate. No examination was made of the role of government policy and bureaucratic excess in these ecological disasters. The erosion on the East Coast, for example, was exacerbated by government subsidies to clear marginal lands. The tailings from gold mines in Otago were the result of legislation in the last century that encouraged mining and placed no restrictions on dumping spoil on the 'waste lands' of the Crown. Nor was there any evidence to indicate that the New Zealand environment was being unsustainably managed. Indeed, despite its focus on sustainable management, the legislation was implemented without any clear and unambiguous definition of the term.

In short, the reform was overtaken by a view that the environment should be managed sustainably, and that only regulation and bureaucratic control could achieve this ideal state. While the legislation purports to be effects-based and to promote market solutions, it remains profoundly regulatory both in intent and practice. Unlike other legislative reform undertaken during this period, the resource management legislation was not soundly based on identified problems, theory and analysis. The underlying concepts of accountability, contestability and transparency, which characterised other legislative reform, are markedly missing from the RMA.

The expected gains from resource management law reform were enhanced efficiency in the administration of the law, and improved environmental protection. Yet with no real baseline, it is impossible to say whether the legislation has been worthwhile in promoting its objective of sustainable management. The reform process was itself costly, and its implementation has involved substantial compliance and administration costs. The real issue is whether the benefits have exceeded the costs. But it is simply not possible to 
establish whether the environment today is worse or better than it would have been without the RMA because there are no data on which to base an analysis (OECD, 1996). Nevertheless, it is possible to point to where the costs of the legislation lie. Restrictions on land use under the RMA seem to engender significant problems for landowners, particularly since they are not accompanied by compensation. At the same time, some land use controls, such as restrictions on the colour farm sheds are painted, do not necessarily contribute social benefits in the form of improved environmental outcomes. The crucial issue is whether preferred environmental outcomes can be better attained by alternatives to this form of regulation.

The transition period of the RMA is now coming to an end. The reforms announced by the Minister appear to represent the start of a more mature phase of resource management. The proposed shift in the focus of the Act is a response to the losses imposed by the current formulation and practice of the Act. Those affected by the Act, such as resource management lawyers, support fine-tuning and improved administration, rather than revisiting the meaning and mechanisms of resource management. Their view that radical change is not warranted reflects their significant investment in institutional capital knowledge of how the current system works - and the costs that they would face in any fundamental change. Yet without some fundamental changes to the underlying premises of the Act, such as the definition of the environment, no real progress can be made. What remains to be seen is whether there is the political will to address these fundamentals by a withdrawal of local and central government from directing resource management and a greater reliance on private incentives and the free market to produce higher quality environmental outcomes (Anderson and Leal, 1997).

The RMA was intended to be a bold and innovative integration of all aspects of environmental protection and resource management within a single statute. It was initially welcomed by landowners, industry and business who foresaw it as an effects-based regime that would reduce their regulatory burden. Their disappointment and dissatisfaction with the administration of the Act by overweening local government and cankerous regulation has led to the promise of change. However, the reform package appears to be addressed largely at procedural rather than fundamental issues. Whether these changes curb regulatory excess and improve the quality of the environment remains to be seen.

\section{References}

Alston, L., T. Eggertsson and D. North (eds) (1996), Empirical Studies in Institutional Change, Cambridge University Press, Cambridge.

Anderson, T. and D. Leal (1997), Enviro-Capitalists: Doing Good while Doing Well, Rowman and Littlefield, Lanham, MD. 
Barlow, C. and J. Quizon (1993), 'The Economics of Institutional Change in Agriculture', Review of Marketing and Agricultural Economics 61(2):263-75.

Bruntiand, G. (1987), Our Common Future, The Commission for the Future, World Commission on Environment and Development.

Dormer, A. (1994), 'The Resource Management Act 1991: The Transition and Business', New Zealand Business Roundtable, Wellington.

Frieder, J. (1997), 'Approaching Sustainability: Integrated Environmental Management and New Zealand's Resource Management Act,' lan Axford New Zealand Fellowship in Public Policy.

Greve, M. and F. Smith Jr. (eds) (1992), Environmental Politics: Public Costs, Private Rewards, Praeger, New York.

Hearn, A. (1987), 'Review of the Town and Country Planning Act', Department of Trade and Industry, Wellington.

Little, R. (1998), 'The Impact on Farm Management Practices; A Practitioner's View', Primary Industry Management 1(1):7-12.

McShane, O. (1998), A 'Think Piece' on Land Use Control under the RMA, a report commissioned by the Minister for the Environment.

Memon, P. and H. Perkins (eds) (1993), Environmental Planning in New Zealand, Dunmore Press, Palmerston North.

Ministry for the Environment (1998), 'Land Use Control Under the Resource Management Act: Analysis of Submissions', Ministry for the Environment, Wellington, June.

North, D. (1990), Institutions, Institutional Change and Economic Performance, Cambridge University Press, Cambridge.

Organisation for Economic Co-operation and Development (1996), New Zealand: Environmental Performance Reviews, Paris.

Perkins, H. and D. Thorns (1997), 'The Debate over Sustainability and City Planning', paper presented at the Regional and Urban Development Conference, Regional Science Association International, Wellington, 8-12 December.

Savage, J. and A. Bollard (1990), Turning it Around: Closure and Revitalization in New Zealand Industry, Oxford University Press, Auckland.

Sharp. B. (1994), 'Resource Management 1984-1994', paper presented to the New Zealand Agricultural Economics Society Annual Conference, Blenheim, 1-2 July.

Wheeler, B. (1998), 'Law, Economics and Resource Management', New Zealand Law Journal August:277-8.

Wilson, G. (1994), 'Towards Sustainable Management of Natural Ecosystems on Farms? A New Zealand Perspective', Journal of Environmental Planning and Management 37(2):171-87.

I am grateful to two anonymous referees for their helpful comments. 